\title{
Elucidating the origin of milk products on the Chinese market using hydrogen and oxygen stable isotope technique
}

\author{
Jingyu Huang ${ }^{1}$, Eyram Norgbey ${ }^{* 1}$, Philip Nti Nkrumah ${ }^{1}$, Gloria Appiah-Sefah ${ }^{1}$ and Rainizafy Michel ${ }^{1}$ \\ ${ }^{1}$ Ministry of Education, Key Laboratory of Integrated Regulation and Resource Development on Shallow Lakes, College of Environment, Hohai University,
} Nanjing, 210098 China

\begin{abstract}
Preference for foreign milk products is the cause of the economically motivated adulteration of milk products on the Chinese market. 42 milk samples from the United States of America, Canada, Southern China, Northern China, Australia and New Zealand were analyzed using $\delta^{2} \mathrm{H}$ and $\delta^{18} \mathrm{O}$ stable isotope technique to differentiate the origin of milk products. An isotope ratio mass spectrometer with a combination of a high-temperature conversion elemental analyzer, Thermo-Fisher was used. Statistical analysis was performed using one-way ANOVA. The study revealed $\delta^{2} \mathrm{H}$ and $\delta^{18} \mathrm{O}$ had a wide range of mean values: 13.86 to $22.25 \% 0$ and -82.86 to $-28.5 \%$, respectively. There was a significant difference in the $\delta^{2} \mathrm{H}(\mathrm{n}=7 ; \mathrm{F}=20880, \mathrm{P}=7.876 \mathrm{E}-43)$ and $\delta^{18} \mathrm{O}(\mathrm{n}=7 ; \mathrm{F}=1399.0 ; \mathrm{P}=9.215 \mathrm{E}-29)$ composition of the milk samples from the different regions. It was observed that $\delta^{2} \mathrm{H}$ and $\delta^{18} \mathrm{O}$ composition is helpful in elucidating milk products from different regions on the Chinese market $(\mathrm{P}<0.05)$.
\end{abstract}

\section{Introduction}

Consumers in China are, for many reasons, asking for information about the food they are purchasing: the authenticity of the food and the geographical location of the food. Food adulteration is prominent in China and consumers are skeptical about the origin of food sold on the Chinese market [1]. Food adulteration affects the quality of food, which poses negative effects on consumers' nutrition and in some cases have led to adverse health effects including death [2]. According to Lu and $\mathrm{Wu}$ [3], criminal cases relating to food safety that include food adulteration grew by $179.8 \%$ and $224.6 \%$ respectively; in 2011 and 2012 in China. Thus, the need to study food fraud issues in China is necessary and timely. Milk is a major issue for the dairy industry in terms of adulteration. Significant profits on dairy items make them a prime target for adulteration [4]. Because Chinese consumers have a high preference for foreign milk products, they are the most vulnerable when it comes to milk adulteration and mislabeling. As it may not be obvious to detect the authenticity via physical observation, there is the urgent need for robust techniques that could provide unequivocal authentication outcome. Stable isotopes of hydrogen $(\mathrm{H})$ and oxygen (O) in milk water are particularly essential for geographical origin assignment of food connected to regional climatic conditions because they are strongly latitude-dependent [5]. The $\delta^{18} \mathrm{O}$ content in milk water reflects the isotope composition of the ground water drunk by animals which in turn depends on the altitude, seasonality, total precipitation and distance from the sea [6]. This implies that it may be possible to discriminate among milk products that are obtained from different geographical origin using hydrogen and oxygen stable isotopic signatures. The main aim of this study is to use the isotopic ratios of $\mathrm{H}$ and $\mathrm{O}$ within the milk, using mass spectroscopy, to reveal the true geographical origin of milk products on the Chinese market and tackle the mislabeling and deception done by local manufacturers.

\section{Materials and methods}

\section{Sample preparation and Statistical analysis}

Forty-two milk samples were collected from different geographical origins, including the United States of America (USA), Canada (CA), Southern part of China (SC), Northern part of China (NC), Australia (AU), New Zealand (NZ). Each $\delta^{2} \mathrm{H}$ and $\delta^{18} \mathrm{O}$ composition of the samples ( $\mathrm{n}=7$ for each region) represent the mean of 3 replicates. Each liquid milk sample was obtained from genuine sources and was $100 \%$ authentic. These samples were provided by GOUSU Testing Co. Limited Nanjing, China. The data obtained were analyzed using descriptive statistics and one-way analysis of variance (ANOVA) in the Excel Analysis ToolPak. A confidence level of 95\% was accepted while an alpha value of 0.05 was used in the -one-way ANOVA. Each $\delta^{18} 0$ and $\delta^{2} \mathrm{H}$ composition of the samples represents the mean of 3 replicates.

\section{Milk water}

Moderate rennet (activity $\geq 105 \mathrm{U} / \mathrm{g}$ ) obtained from the USA was added to pure milk and the samples were left overnight at room temperature. After, the milk water was collected by filtration and then frozen at $-20^{\circ} \mathrm{C}$ until analysis.

Correspondence to: Eyram Norgbey, Ministry of Education, Key Laboratory of Integrated Regulation and Resource Development on Shallow Lakes, College of Environment, Hohai University, Nanjing, 210098 China, Tel: 8613813966025; E-mail: eyramnorgbey@outlook.com

Key words: food safety, pure milk, economically motivated adulteration, stable isotope ratios, origin

Received: March 05, 2017; Accepted: March 27, 2017; Published: March 31, 2017 


\section{Standards}

Stable isotope ratios are expressed in delta $(\delta)$ notation, was used to describe the isotopic difference between the sample and an international standard, which is defined by the equation.

$$
\delta(\%)=\left[\left(\mathrm{R}_{\mathrm{s}} / \mathrm{R}_{\text {std }}\right)-1\right] \times 1000
$$

where $\mathrm{R}_{\mathrm{s}}$ was the isotope ratio (i.e., ${ }^{2} \mathrm{H} /{ }^{1} \mathrm{H}$, and ${ }^{18} \mathrm{O} /{ }^{16} \mathrm{O}$ ) of the sample, and $\mathrm{R}_{\text {std }}$ was that of the reference materials. Variations in stable isotope ratios were reported as parts per thousand (\%o) deviations from internationally accepted standards: Vienna Standard Mean Ocean Water (VSMOW) for oxygen and hydrogen.

\section{Measurements}

The liquid milk samples were analyzed using an isotope ratio mass spectrometer (IRMS) operating in the continuous flow mode (Integra CN, Sercon, Cershire, UK) with a combination of a hightemperature conversion elemental analyzer (TC/EA) attached Flash Element Analyzer 1112 HT-Delta V advantage, Thermo-Fisher for oxygen isotope analysis. For hydrogen isotopic analysis, the IRMS was equipped with an energy filter to suppress ${ }^{+4} \mathrm{He}$ ions on the attached Flash EA 1112 HT-Delta V advantage, Thermo-Fisher. The reactor consists of a glassy carbon tube with glassy carbon filling, ensuring that neither sample nor reaction gasses can get into contact with oxygencontaining surfaces. The reaction gasses are separated in an isothermal gas chromatograph, which is also part of the TC/EA. The gasses were admitted to the IRMS for isotope analysis. Measurements were made using calibration of the system with reference hydrogen and oxygen gas and reference standard material of VSMOW in regular repetitions.

\section{Results}

The mean $\delta^{2} \mathrm{H}$ and $\delta^{18} \mathrm{O}$ composition of milk samples are shown in Table 1 respectively. The range of the mean values for $\delta^{2} \mathrm{H}$ and $\delta^{18} \mathrm{O}$ are $-82.86 \pm 0.26$ to $-28.50 \pm 0.17 \%$ ond $13.86 \pm 0.30$ to $22.25 \pm 0.34 \%$ o respectively. The difference in the $\delta^{2} \mathrm{H}(\mathrm{F}=20880 ; \mathrm{P}=7.876 \mathrm{E}-43 ; \mathrm{n}=7)$ and $\delta^{18} \mathrm{O}(\mathrm{F}=1399.0 ; \mathrm{P}=9.215 \mathrm{E}-29 ; \mathrm{n}=7)$ composition of the samples were highly significant. Table 2 shows discriminating between the regions-of-origins of milk using oxygen and hydrogen stable isotope technique

\section{Discussion}

Stable isotope analysis of is a powerful tool for provenance determination of food materials because isotopic compositions of the materials reflect many factors in the natural environment [7]. Renou et al. [8] indicated stable isotope analysis can be a useful tool in showing a clear disparity between milk products from different regions. Studies indicate that the $\mathrm{H}$ and $\mathrm{O}$ stable isotope values of animal tissue correlate with the isotopic composition of local precipitation [9]. The $\delta^{2} \mathrm{H}$ and $\delta^{18} \mathrm{O}$ composition in water consumed by animals shows a strong correlation with the $\delta^{2} \mathrm{H}$ and $\delta^{18} \mathrm{O}$ content present in animal products such as milk [10]. Particularly, Chesson et al. [11] established that the $\delta^{2} \mathrm{H}$ and $\delta^{18} \mathrm{O}$ value of milk water show the isotopic composition of drinking water and water consumed from fresh forage, with minor deviations due to the contribution of food and atmospheric oxygen to the water body. According to Simpkins et al. [12], the predominant influence on the fractionation of $\mathrm{H}$ and $\mathrm{O}$ isotopes is evaporation of water, which is reliant on climatic conditions such as humidity, temperature and rainfall. Moreover, the primary driver of the systematic geospatial patterns of $\mathrm{H}$ and $\mathrm{O}$ isotope ratios in precipitation are the preferential stripping of the heavy isotopes (i.e., ${ }^{2} \mathrm{H}$ and ${ }^{18} \mathrm{O}$ ) from water vapor as ocean-saturated air masses move inland and across continents. Hence, at global to regional scales, the spatial variation in the isotopic composition of environmental water resources and human drinking water is consistent with the geographic patterns of precipitation isotopes. Studies indicate that as the $\delta^{2} \mathrm{H}$ and $\delta^{18} \mathrm{O}$ content of local water are related to the climatic and geographical features of an area, milk water with $\delta^{2} \mathrm{H}$ and $\delta^{18} \mathrm{O}$ can distinguish between milk produced in different areas[11,13].

From the present study, a very high significant difference in the $\delta^{2} \mathrm{H}$ and $\delta^{18} \mathrm{O}$ composition of milk water having a probability of $9.678 \mathrm{E}-6$ and 9.215E-29 respectively $(\mathrm{P}<0.05)$ were obtained from the regions under consideration (Table 1). As shown in Table 2, the variation in $\delta^{2} \mathrm{H}$ values by geographical origin showed there were high significant differences in following regions when compared: USA vs. CA, AU vs. $\mathrm{NZ}$, SC $v s$. NC, USA vs. AU, USA vs. NZ, USA vs. NC, USA vs. SC, SC vs. AU, SC vs. NZ, SC vs. CA, NC vs. AU, NC vs. NZ, NC vs. CA, AU vs. CA, NZ vs. CA. Also from Table 2, the variation in $\delta^{18} \mathrm{O}$ values by geographical origin also showed there were high significant differences in following regions when compared: USA vs. CA, AU vs. NZ, SC vs. $\mathrm{NC}, \mathrm{USA} v s . \mathrm{AU}, \mathrm{USA} v s$. NZ, USA $v s$. NC, USA vs. SC, SC vs. AU, SC vs. $\mathrm{NZ}, \mathrm{SC} v s$. CA, NC vs. AU, NC vs. CA, AU vs. CA, NZ vs. CA. Showing a $\mathrm{P}$ value less than 0.05 which indicate that $\delta^{2} \mathrm{H}$ and $\delta^{18} \mathrm{O}$ values in the milk sample can differentiate between the regions under study when compared, show the true geographical origin of milk. So in an instance when a fraudster insists his milk product is from a particular region, it is possible to authenticate the geographical region of the milk product using hydrogen and oxygen stable isotope technique. The extremely

Table 1. The mean $\pm \mathrm{SD} \delta^{18} \mathrm{O}$ and $\delta^{2} \mathrm{H}$ isotopic composition of milk samples from all the regions under consideration.

\begin{tabular}{|c|c|c|}
\hline Regions & $\boldsymbol{\delta}^{\mathbf{1 8}} \mathbf{O}$ composition (\%o) & $\boldsymbol{\delta}^{\mathbf{2}} \mathbf{H}$ composition (\%o) \\
\hline USA & $13.86 \pm 0.30$ & $-65.93 \pm 0.32$ \\
\hline Canada & $17.35 \pm 0.42$ & $-82.86 \pm 0.26$ \\
\hline Southern part of China & $20.41 \pm 0.40$ & $-31.37 \pm 0.18$ \\
\hline Northern part of China & $21.63 \pm 0.25$ & $-28.50 \pm 0.17$ \\
\hline Australia & $22.25 \pm 0.34$ & $-39.73 \pm 0.16$ \\
\hline New Zealand & $21.62 \pm 0.25$ & $-63.95 \pm 0.39$ \\
\hline Statistical analysis & $\mathrm{n}=7 ; \mathrm{F}=1399.0 ; \mathrm{P}=9.215 \mathrm{E}-29$ & $\mathrm{n}=7 ; \mathrm{F}=20880 ; \mathrm{P}=7.876 \mathrm{E}-43$ \\
\hline
\end{tabular}

Descriptive statistics; $\alpha=0.05$, Confidence level $=95 \%$ (one-way ANOVA).

Each $\delta^{18} 0$ and $\delta^{2} \mathrm{H}$ composition of the samples represents the mean of 3 replicates.

Table 2. Discriminating between the regions-of-origins of milk using Oxygen and Hydrogen stable isotope technique.

\begin{tabular}{|c|c|c|c|c|}
\hline \multirow{2}{*}{ Regions } & \multicolumn{2}{|c|}{$\begin{array}{c}\text { Oxygen Isotope } \\
\text { Analysis }\end{array}$} & \multicolumn{2}{c|}{$\begin{array}{r}\text { Hydrogen Isotope } \\
\text { Analysis }\end{array}$} \\
\cline { 2 - 5 } & P & Feasibility & P & Feasibility \\
\hline USA vs. Canada & $2.27 \mathrm{E}-9$ & Yes & $3.176 \mathrm{E}-13$ & Yes \\
\hline Australia vs. New Zealand & 0.0004262 & Yes & $6.068 \mathrm{E}-14$ & Yes \\
\hline $\begin{array}{c}\text { Southern part of China vs. Northern } \\
\text { part of China }\end{array}$ & $2.2408 \mathrm{E}-5$ & Yes & $1.427 \mathrm{E}-6$ & Yes \\
\hline USA vs. Australia & $2.146 \mathrm{E}-12$ & Yes & $1.904 \mathrm{E}-14$ & Yes \\
\hline USA vs. New Zealand & $9.146 \mathrm{E}-13$ & Yes & $9.678 \mathrm{E}-6$ & Yes \\
\hline USA vs. Northern part of China & $2.0566 \mathrm{E}-$ & Yes & $5.9104 \mathrm{E}-$ & Yes \\
\hline USA vs. Southern part of China & $4.732 \mathrm{E}-11$ & Yes & $2.901 \mathrm{E}-15$ & Yes \\
\hline Southern part of China vs. Australia & $1.558 \mathrm{E}-6$ & Yes & $5.074 \mathrm{E}-10$ & Yes \\
\hline Southern part of China vs. New Zealand & $1.5531 \mathrm{E}-5$ & Yes & $7.596 \mathrm{E}-15$ & Yes \\
\hline Southern part of China vs. Canada & $2.871 \mathrm{E}-8$ & Yes & $1.511 \mathrm{E}-16$ & Yes \\
\hline Northern part of China vs. Australia & 0.0009054 & Yes & $2.236 \mathrm{E}-11$ & Yes \\
\hline Northern part of China vs. New Zealand & 0.8615 & No & $1.686 \mathrm{E}-15$ & Yes \\
\hline Northern part of China vs. Canada & $4.2271 \mathrm{E}-10$ & Yes & $4.2271 \mathrm{E}-10$ & Yes \\
\hline Australia vs. Canada & $2.558 \mathrm{E}-10$ & Yes & $4.557 \mathrm{E}-16$ & Yes \\
\hline New Zealand vs. Canada & $2.161 \mathrm{E}-10$ & Yes & $2.442 \mathrm{E}-13$ & Yes \\
\hline
\end{tabular}


high significant difference observed in the samples obtained from different regions-of-origins is explained by the geographic variation in water isotope ratios. However, $\mathrm{O}$ stable isotope technique failed to provide a unique distinction between the milk samples obtained from the Northern part of China and New Zealand $(\mathrm{P}=0.8615)$. This may be due to the fact that animals may have a similar diet which supports works by Renou et al [8]. Ritz et al. [14] also explained that difference in the type of breed and difference in time elapsed since last pregnancy of the milk producing animal can also affect the $\delta^{18} \mathrm{O}$ composition. Also, similar climatic conditions within the production regions may be the cause. This is because the content of $\delta^{18} \mathrm{O}$ depends on climatic conditions [5]. In a past study [6], stable isotope values were utilized to develop a new analytical approach enabling the identification of milk samples from different geographical origins. The results they found were quite consistent with our results, which is that milk samples from the six different regions, the United States of America, Canada, Southern China, Northern China, Australia and New Zealand, could be easily discriminated and classified by $\delta^{2} \mathrm{H}$ and $\delta^{18} \mathrm{O}$.

As a result of the extreme significant difference in the $\delta^{2} \mathrm{H}$ and $\delta^{18} \mathrm{O}$ composition of the milk samples obtained from the different geographical regions, fraudulent manufacturers cannot label milk products obtained from China as a milk obtained from a different geographical region. From our study, $\mathrm{H}$ and $\mathrm{O}$ stable isotope techniques may be useful in providing a unique discrimination in the origin of production of commercially distributed milk on the Chinese market. And thus could easily prevent the cheat of domestic pure milk to foreign pure milk or mislabeling pure milk.

\section{Conclusions}

China exports food to most parts of the world and it is not uncommon to find substandard products or mislabeled products in the Chinese market. Thus it is important that food exported to other countries from China are genuine and consumers are given what they have paid for. In this study, stable hydrogen and oxygen isotopic compositions $\left(\delta^{2} \mathrm{H}, \delta^{18} \mathrm{O}\right)$ of 42 pure milk from various cultivated areas (the United States of America, Canada, Southern China, Northern China, Australia and New Zealand), were applied to discriminate the geographical origin of pure milk. It is clear from our discussions above that it is possible with varying degrees of certainty to determine the geographical origin of milk using $\delta^{2} \mathrm{H}$, and $\delta^{18} \mathrm{O}$.

\section{Conflicts of interest}

All authors consent to submit to this Journal and there is any conflict of interest.

\section{Acknowledgement}

The authors are grateful for the financial support from the Fundamental Research Funds for the Central University (2015B16214). A project funded by the Priority Academic Program Development of Jiangsu Higher Education Institutions.

\section{References}

1. Huang J, Nkrumah PN, Appiah-Sefah G, Tang S (2013) Authentication of pure L-Leucine products manufactured in china by discriminating between plant and anima sources using nitrogen stable isotope technique. J Food Sci 78: H490-H494. [Crossref]

2. Gossner CM, Schlundt J, Ben Embarek P, Hird S, Lo-Fo-Wong D, et al. (2009) The melamine incident: implications for international food and feed safety. Environ Health Perspect 117: 1803-1808. [Crossref]

3. Lu F, Wu X (2014) China food safety hits the "gutter". Food Control 41:134-138.

4. Xue J, Zhang W (2013) Understanding China's food safety problem: An analysis of 2387 incidents of acute foodborne illness. Food Control 30: 311-317.

5. Kelly SD (2003) Using stable isotope ratio mass spectrometry (IRMS) in food authentication and traceability. Food Authent traceability. 2003: 156.

6. Luo D, Dong H, Luo H, Xian Y, Guo X, et al. (2015) Multi-Element (C, N, H, O) Stable Isotope Ratio Analysis for Determining the Geographical Origin of Pure Milk from Different Regions. Food Anal Methods [Internet].

7. Nakashita R, Suzuki Y, Akamatsu F, Iizumi Y, Korenaga T, et al. (2008) Stable carbon, nitrogen, and oxygen isotope analysis as a potential tool for verifying geographical origin of beef. Anal Chim Acta 617: 148-152. [Crossref]

8. Renou J, Deponge C, Gachon P, Bonnefoy J, Ritz P (2004) Characterization of animal products according to geographic origin and feeding diet using nuclear magnetic resonance and isotope ratio mass spectrometry: cow milk. Food Chemistry 85: 63-66.

9. Ehleringer JR, Bowen GJ, Chesson LA, West AG, Podlesak DW, et al. (2008) Hydrogen and oxygen isotope ratios in human hair are related to geography. Proc Natl Acad Sci USA 105: 2788-2793. [Crossref]

10. Kelly S, Heaton K, Hoogewerff J (2005) Tracing the geographical origin of food: The application of multi-element and multi-isotope analysis. Trends Food Sci Technol 16: 555-567.

11. Chesson LA, Valenzuela LO, O'Grady SP, Cerling TE, Ehleringer JR (2010) Hydrogen and oxygen stable isotope ratios of milk in the United States. J Agric Food Chem 58: 2358-2363. [Crossref]

12. Simpkins WA, Patel G, Collins P, Harrison M, Goldberg D (1999) Oxygen isotope ratios of juice water in Australian oranges and concentrates. J Agric Food Chem 47: 2606-2612. [Crossref]

13. Bontempo L, Lombardi G, Paoletti R, Ziller L, Camin F (2012) H, C, N and O stable isotope characteristics of alpine forage, milk and cheese. Int Dairy J 23: 99-104.

14. Ritz P, Gachon P, Garel J, Bonnefoy J, Coulon J, et al. (2005) Milk characterization: effect of the breed. Food Chemistry 91: 521-523.

Copyright: (C2017 Huang J. This is an open-access article distributed under the terms of the Creative Commons Attribution License, which permits unrestricted use, distribution, and reproduction in any medium, provided the original author and source are credited. 